\title{
Qualidade e potencial nutracêutico do leite bovino em diferentes sistemas de produção e estações do ano
}

\author{
Diego Prado de Vargas( ${ }^{(1)}$, José Laerte Nörnberg(1), Rudolf Brand Scheibler(2), Jorge Schafhauser Junior ${ }^{(3)}$, \\ Fábio Antunes Rizzo ${ }^{(2)}$ e Roger Wagner ${ }^{(1)}$
}

\begin{abstract}
(1)Universidade Federal de Santa Maria, Departamento de Tecnologia e Ciência dos Alimentos, Avenida Roraima, no 1.000, Cidade Universitária, Bairro Camobi, CEP 97105-900 Santa Maria, RS, Brasil. E-mail: diegodevargas@hotmail.com, jlnornberg@gmail.com, rogerwag@gmail.com (2)Universidade Federal de Pelotas, Departamento de Zootecnia, Rua Gomes Carneiro, no 01, Centro, CEP 96010-610 Pelotas, RS, Brasil. E-mail: rudolfbrandscheibler@hotmail.com, rizzo.fabioantunes@gmail.com ${ }^{(3)}$ Embrapa Clima Temperado, Caixa Postal 403, CEP 96010-971 Pelotas, RS, Brasil. E-mail: jorge.junior@embrapa.br
\end{abstract}

Resumo - O objetivo deste trabalho foi avaliar o efeito da interação entre sistemas produtivos e estações do ano sobre a qualidade química e microbiológica do leite bovino, além de propor um índice de potencial nutracêutico do perfil de ácidos graxos do leite. Três propriedades foram avaliadas mensalmente, durante as diferentes estações do ano, em quatro graus de especialização dos sistemas de produção: altamente especializado, especializado, semiespecializado e não especializado. Os sistemas de produção e as estações do ano interferem de forma conjunta no perfil de ácidos graxos e, de forma isolada, na qualidade química e microbiológica do leite. As maiores contagens de células somáticas e os menores conteúdos de proteína foram observados no verão, e o grau de especialização das unidades produtivas esteve indiretamente relacionado à contagem bacteriana total no leite. No inverno, sistemas não especializados produziram leite com o melhor índice nutracêutico, que apresentaram os maiores teores de ácidos graxos poli-insaturados, ácido rumênico (CLA, 18:2n7-c9,t11) e ácido t10,c12-octadecadienoico (CLA, 18:2n6-t10,c12).

Termos para indexação: ácido linoleico conjugado, alimentos funcionais, perfil de ácidos graxos, qualidade do leite bovino.

\section{Quality and nutraceutical potential of bovine milk in different production systems and seasons}

\begin{abstract}
The objective of this work was to evaluate the effect of the interaction between production systems and seasons on the chemical and microbiological qualities of bovine milk, besides proposing a potential nutraceutical index of milk fatty acid profiles. Three farms were assessed monthly, along the different seasons, for four specialization levels of the production systems: highly specialized, specialized, partially specialized, and nonspecialized. The production systems and the seasons jointly interfere in fatty acid profiles, and singly interfere in the chemical and microbiological quality of milk. The highest somatic cell counts and the lowest protein contents were observed in the summer, and the specialization level of the production units had an inverse relationship with the total bacterial count. During winter, nonspecialized systems produced milk with the best nutraceutical index, with the highest contents of polyunsaturated fatty acids, rumenic acid (CLA, 18:2n7-c9,t11) and t10,c12-octadecadienoic acid (CLA, 18:2n6-t10,c12).
\end{abstract}

Index terms: conjugated linoleic acid, functional foods, fatty acid profiles, bovine milk quality.

\section{Introdução}

O leite é produzido com expressiva heterogeneidade de sistemas de produção, em todo o território brasileiro, com menor número de produtores especializados (sistemas intensivos de produção) e elevado número de produtores com intermediária ou nenhuma especialização (sistemas extrativistas de produção). Esses sistemas diferem, principalmente, pela produtividade leiteira e pelo manejo nutricional e higiênico-sanitário adotado (Gabbi et al., 2013).

Para a cadeia láctea mundial, é de grande relevância identificar os sistemas de manejo e produção de rebanhos leiteiros que favoreçam a obtenção de leite com maior qualidade, ao longo das diferentes estações do ano (Bodenmüller Filho et al., 2010).

Quanto à qualidade do leite, do ponto de vista legal e prático, consideram-se a composição centesimal - que 
inclui os teores de gordura, proteína e sólidos totais - e os aspectos higiênico-sanitários, que englobam padrões internacionais relacionados à contagem de células somáticas (CCS) e à contagem bacteriana total (CBT) (Vargas et al., 2013, 2014).

Com o maior acesso à informação sobre o papel dos alimentos na saúde, o conceito de qualidade temse tornado mais abrangente. Assim, uma nova classe de alimentos tem surgido, denominada de "alimentos nutracêuticos", capazes de proporcionar benefícios à saúde do consumidor, que incluem prevenção ou tratamento de doenças (Tripathi, 2014).

Com foco no potencial nutracêutico de alguns ácidos graxos, tem-se buscado a elevação dos conteúdos de ácido rumênico (CLA, 18:2n7-c9,t11) e ácido t10,c12-octadecadienoico (CLA, 18:2n6-t10,c12) no leite, que podem contribuir para a prevenção e combate de muitas doenças em humanos, como obesidade, doenças cardiovasculares, diabetes do tipo-2, e alguns tipos de câncer (Kratz et al., 2013; Lahlou et al., 2014).

Sistemas de produção e estações do ano podem interferir na qualidade química e microbiológica do leite (Gabbi et al., 2013); porém, há pouca informação disponível quanto ao efeito conjunto desses fatores sobre a qualidade e o potencial nutracêutico do leite.

O objetivo deste trabalho foi avaliar o efeito da interação entre sistemas de produção e estações do ano sobre a qualidade química e microbiológica do leite bovino, além de propor um índice de potencial nutracêutico do perfil de ácidos graxos.

\section{Material e Métodos}

Três propriedades foram avaliadas, mensalmente, durante as diferentes estações do ano, em quatro graus de especialização dos sistemas de produção: altamente especializado, especializado, semiespecializado e não especializado (Tabela 1), tendo-se analisado um total de 144 amostras, de 12 propriedades.

As amostras foram coletadas em 2012, em fazendas localizadas em municípios compreendidos desde a Região Central do Rio Grande do Sul até o início da Serra Gaúcha $\left(29^{\circ} 15^{\prime} 16^{\prime \prime}\right.$ a $29^{\circ} 29^{\prime} 13^{\prime \prime S}$; e $51^{\circ} 31^{\prime} 52^{\prime \prime}$ a $\left.51^{\circ} 59^{\prime} 50^{\prime \prime} \mathrm{W}\right)$. Paralelamente, foram coletadas amostras dos alimentos destinados aos animais, para sua caracterização (Tabela 2). Os lipídeos foram extraídos das amostras de leite e de alimento - silagem de milho, concentrado, pastagens temperadas (aveia-preta,
Avena strigosa, e azevém, Lolium multiflorum) e pastagens tropicais (capim-sudão, Sorghum sudanense, e milheto, Pennisetum glaucum), conforme Bligh \& Dyer (1959). A transesterificação e a metilação seguiram a técnica descrita por Christie (1982). O perfil de ácidos graxos foi determinado de acordo com Simionato et al. (2010). A identificação dos ésteres metílicos de ácidos graxos (Emag) foi realizada pela comparação dos tempos de retenção dos constituintes da amostra, tendo-se utilizado mistura composta de 37 Emag (24056, Supelco, 37 Component Fame Mix) e padrão do éster metílico do ácido transvacênico (18:1n7-t11) (46905-U, trans-11-octadecenoic methyl ester), com mistura dos isômeros do éster metílico do ácido rumênico (CLA, 18:2n7-c9,t11) e ácido t10,c12-octadecadienoico (CLA, 18:2n6-t10,c12) (O5632, Linoleic acid, conjugated methyl ester).

As amostras de alimento foram expressas em

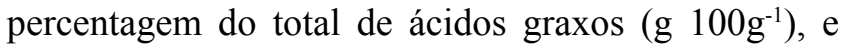
as de leite em lipídeos totais $\left(\mathrm{mg} \mathrm{g}^{-1}\right)$, em relação ao padrão interno [tricosanoato de metila (23:0) (T9900, methyl tricosanoate)]. Os cálculos foram realizados conforme Simionato et al. (2010), com a equação: $\mathrm{C}\left(\mathrm{mg} \mathrm{g}^{-1}\right)=\left(\mathrm{A}_{\mathrm{x}} \times \mathrm{m}_{23: 0} \times \mathrm{F}_{\mathrm{RT}}\right) /\left(\mathrm{A}_{23: 0} \times \mathrm{M}_{\mathrm{A}} \times \mathrm{F}_{\mathrm{CT}}\right), \mathrm{em}$ que $A_{X}$ é a área dos ésteres metílicos dos ácidos graxos; $\mathrm{A}_{23: 0}$, a área do padrão interno; $\mathrm{m}_{23: 0}$, a massa do padrão interno adicionado à amostra $(\mathrm{em} \mathrm{mg}) ; \mathrm{M}_{\mathrm{A}}$, a massa da amostra (em g); $F_{R T}$, o fator teórico de resposta dos ésteres metílicos de ácidos graxos; $\mathrm{F}_{\mathrm{CT}}$, o fator de conversão para expressão dos resultados em miligramas de ácidos graxos por grama de lipídeos totais.

Os resultados da determinação dos ácidos graxos do leite foram utilizados para calcular os índices de aterogenicidade e trombogenicidade (Ulbricht \& Southgate, 1991), bem como a razão entre ácidos graxos hipocolesterolêmicos e hipercolesterolêmicos (Santos-Silva et al., 2002) e ácidos graxos desejáveis (AGD) (Costa et al., 2008). O índice de AGD leva em consideração o somatório de ácidos graxos monoinsaturados ( $\Sigma$ AGMI), poli-insaturados ( $\Sigma$ AGPI) e o ácido esteárico (C18:0), e não somente os ácidos com reconhecido potencial nutracêutico. Portanto, este estudo propõe uma equação, com ácidos graxos que apresentem esse potencial, denominada de índice nutracêutico do leite bovino (IN): $\mathrm{IN}=$ (ácido transvacênico + ácido rumênico + ácido

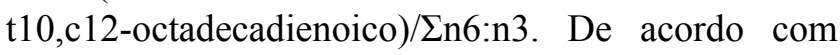
a equação, o numerador é diretamente proporcional 
à concentração de ácidos graxos benéficos à saúde, e inversamente proporcional à relação ômega 6 e ômega 3 ( n6:n3), o que está de acordo com a diminuição recomendada nesta razão (Simopoulos, 2006).

Os teores de gordura, proteína, lactose e sólidos totais do leite foram determinados em equipamento Bentley 2000; enquanto a CCS e a CBT foram obtidas por citometria de fluxo, em equipamento Somacount 300 e Bactocount IBC, respectivamente. Com o intuito de linearizar os dados, a CCS foi transformada em escore linear de células somáticas para $\mathrm{ECS}=[\log 2(\mathrm{CCS} / 100)]+3$ (Shook, 1993), e a CBT, transformada pelo logaritmo natural da CBT normal.

Os resultados foram analisados conforme delineamento inteiramente casualizado, com medidas repetidas no tempo, tendo-se utilizado o procedimento
Mixed e empregado estrutura paramétrica especial nas matrizes de variância e covariância, conforme o modelo estatístico: $\mathrm{Y}_{\mathrm{ijk}}=\mu+\alpha_{\mathrm{i}}+\gamma_{\mathrm{k}}+(\alpha \gamma)_{\mathrm{ik}}+\varepsilon_{\mathrm{ijk}}$, em que: $\mathrm{Y}_{\mathrm{ijk}}$ é o valor observado pela k-ésima estação e j-ésima UPL, do i-ésimo sistema produtivo; $\mu+\alpha_{\mathrm{i}}+\gamma_{\mathrm{k}}+(\alpha \gamma)_{\mathrm{ik}}$ é a média para o sistema produtivo i, na estação $\mathrm{k}$, que contém os efeitos fixos para o sistema produtivo i, estação k, bem como a interação sistema produtivo $\times$ estação ik; e $\varepsilon_{\mathrm{ijk}}$ é o erro aleatório, associado à mensuração na estação $\mathrm{k}$ na $\mathrm{j}$-ésima unidade de produção de leite (UPL), designada ao sistema produtivo i. Assumiu-se uma estrutura de medidas repetidas para os resíduos; ou seja, utilizaram-se os pressupostos de que $\varepsilon_{\mathrm{ijk}} \sim \mathrm{N}$ $\left(0 ; \sum\right)$, em que: $\sum$ representa a matriz de covariância e covariância residual que mais adequou-se aos dados. As matrizes testadas foram: AR (1), autorregressiva

Tabela 1. Características dos sistemas de produção de leite altamente especializado (AE), especializado(ES), semiespecializado (SE) e não especializado (NE).

\begin{tabular}{|c|c|c|c|c|c|c|c|c|}
\hline Sistema & $\begin{array}{c}\text { Produção } \\
\text { (L por animal por dia) }\end{array}$ & $\begin{array}{l}\text { Área } \\
\text { (ha) }\end{array}$ & $\begin{array}{c}\text { Concentrado } \\
(\mathrm{kg} \text { por vaca por dia) }\end{array}$ & Silagem $^{(1)}$ & Raça & Ordenha & Local & Refrigeração \\
\hline Altamente especializado & $>20$ & $>15$ & $>10$ & Sim & Definida & Circuito fechado & Sala própria & Com \\
\hline Especializado & $15-20$ & $10-15$ & $4-10$ & Sim & Definida & Circuito aberto & Sala própria & Com \\
\hline Semiespecializado & $10-15$ & $5-10$ & $1-4$ & Sim & Não definida & Balde ao pé & Galpão & Com \\
\hline Não especializado & $5-10$ & $1-5$ & $<1$ & Não & Não definida & Balde ao pé & Galpão & Sem \\
\hline
\end{tabular}

(1)Sim, silagem de milho como base do volumoso diário; Não, silagem de milho como parte do volumoso diário.

Tabela 2. Caracterização do perfil de ácidos graxos (g $100 \mathrm{~g}^{-1}$ do total de ácidos graxos), dos principais constituintes da dieta recebida pelos animais, nos sistemas de produção altamente especializado (AE), especializado (ES), semiespecializado (SE) e não especializado (NE).

\begin{tabular}{|c|c|c|c|c|c|c|c|c|c|c|c|c|c|c|c|c|}
\hline \multirow[t]{2}{*}{ Ácido graxo } & \multicolumn{4}{|c|}{ Silagem de milho } & \multicolumn{4}{|c|}{ Concentrado } & \multicolumn{4}{|c|}{ Pastagem temperada $^{(1)}$} & \multicolumn{4}{|c|}{ Pastagem tropical ${ }^{(2)}$} \\
\hline & $\mathrm{AE}$ & ES & SE & $\mathrm{NE}$ & $\mathrm{AE}$ & ES & SE & $\mathrm{NE}$ & $\mathrm{AE}$ & ES & $\mathrm{SE}$ & $\mathrm{NE}$ & $\mathrm{AE}$ & ES & $\mathrm{SE}$ & $\mathrm{NE}$ \\
\hline 12:0 (ácido láurico) & 0,20 & 0,24 & 0,28 & - & 0,10 & 0,15 & 0,14 & 0,12 & 2,08 & 2,11 & 2,16 & 2,20 & 2,87 & 2,64 & 2,49 & 2,94 \\
\hline 14:0 (ácido mirístico) & 0,40 & 0,50 & 0,47 & - & 8,25 & 7,22 & 8,22 & 7,27 & 0,45 & 0,40 & 0,50 & 0,61 & 0,50 & 0,45 & 0,54 & 0,90 \\
\hline 16:0 (ácido palmítico) & 16,20 & 16,18 & 16,80 & - & 21,40 & 21,70 & 22,40 & 22,90 & 13,20 & 13,00 & 13,14 & 13,11 & 20,02 & 20,00 & 19,77 & 18,44 \\
\hline 16:1n7-c9 (ácido palmitoleico) & 0,50 & 0,39 & 0,40 & - & 0,20 & 0,19 & 0,15 & 0,15 & 0,15 & 0,20 & 0,12 & 0,18 & 2,14 & 1,18 & 2,11 & 1,94 \\
\hline 18:0 (ácido esteárico) & 2,10 & 2,08 & 2,06 & - & 3,60 & 3,62 & 3,48 & 3,76 & 2,47 & 2,42 & 2,40 & 2,49 & 5,21 & 5,87 & 5,77 & 5,02 \\
\hline 18:1n9-c9 (ácido oleico) & 13,15 & 12,10 & 11,00 & - & 18,02 & 18,60 & 18,65 & 18,02 & 2,48 & 2,49 & 2,60 & 2,70 & 9,80 & 7,95 & 7,80 & 7,87 \\
\hline 18:2n6-c9,c12 (ácido linoleico) & 27,80 & 28,50 & 28,80 & - & 35,94 & 33,49 & 33,86 & 35,94 & 12,00 & 11,00 & 11,50 & 14,20 & 17,04 & 20,14 & 20,05 & 19,94 \\
\hline 18:3n3-c9,c12,c15 (AAL) & 20,30 & 23,60 & 25,80 & - & 3,34 & 3,50 & 3,70 & 3,54 & 55,22 & 55,48 & 54,12 & 50,98 & 27,04 & 28,21 & 26,24 & 28,00 \\
\hline 20:0 (ácido araquídico) & 0,47 & 0,42 & 0,50 & - & 1,98 & 0,88 & 0,98 & 0,98 & 0,57 & 0,50 & 0,77 & 0,81 & 0,52 & 0,48 & 0,43 & 0,41 \\
\hline $20: 1$ & 9,54 & 8,60 & 7,50 & - & 0,66 & 0,67 & 0,40 & 0,76 & 0,34 & 0,57 & 0,45 & 0,34 & 0,50 & 0,52 & 0,77 & 0,82 \\
\hline 21:0 (ácido heneicosanoico) & 0,15 & 0,12 & 0,17 & - & 0,26 & 0,36 & 0,18 & 0,26 & 0,87 & 0,80 & 0,91 & 0,85 & 0,90 & 0,96 & 1,15 & 1,00 \\
\hline $20: 02$ & 0,10 & 0,11 & 0,13 & - & 0,13 & 0,14 & 0,16 & 0,16 & 0,57 & 0,70 & 0,80 & 0,82 & 0,40 & 0,50 & 0,54 & 0,74 \\
\hline 22:0 (ácido behênico) & 2,33 & 1,33 & 1,13 & - & 0,60 & 0,55 & 0,50 & 0,80 & 0,55 & 0,52 & 0,54 & 0,55 & 2,64 & 2,66 & 2,60 & 3,10 \\
\hline 24:0 (ácido lignocérico) & 0,89 & 0,59 & 0,90 & - & 1,12 & 1,17 & 1,20 & 1,22 & 0,61 & 0,70 & 0,48 & 0,77 & 2,90 & 2,94 & 2,80 & 2,61 \\
\hline Não identificados & 5,87 & 5,24 & 4,06 & - & 4,40 & 7,46 & 5,98 & 4,12 & 8,44 & 9,11 & 9,51 & 9,39 & 7,52 & 5,50 & 6,94 & 6,27 \\
\hline
\end{tabular}

${ }^{(1)}$ Aveia-preta (Avena strigosa) e azevém (Lolium multiflorum). ${ }^{(2)}$ Capim-sudão (Sorghum sudanense) e milheto (Pennisetum glaucum). AAL, ácido $\alpha$-linolênico. 
de primeira ordem; VC, componentes de variância; $\mathrm{CS}$, simetria composta; $\mathrm{ARH}(1)$, autorregressiva heterogênea de primeira ordem; $\operatorname{ARMA}(1,1)$, média móvel autorregressiva de primeira ordem; e; TOEP, Toeplitz. As medidas foram estimadas com o comando LSMeans e comparadas pelo teste de Tukey, a 5\% de probabilidade.

No conjunto original das variáveis que representam o potencial nutracêutico do leite, procedeu-se à análise de variância multivariada pelo procedimento GLM e o comando Manova, tendo-se realizado o teste de Wilks para testar a hipótese de que os vetores de médias das diferentes combinações entre sistemas produtivos e estações eram nulos.

Em seguida, utilizou-se a análise de componentes principais (ACP), seguida da análise de agrupamento, com uso do algoritmo hierárquico aglomerativo de Ward como método de agrupamento, e a distância euclidiana quadrática, como medida de dissimilaridade.

As análises estatísticas foram realizadas com o aplicativo SAS, versão 9.0 (SAS Institute Inc., Cary, NC, USA).

\section{Resultados e Discussão}

As estações do ano produziram efeito significativo sobre os teores de proteína e sólidos totais, assim como sobre a CCS (Tabela 3). O teor de proteína foi menor durante o verão, em razão da baixa qualidade nutricional das pastagens tropicais (Sorghum sudanense e Pennisetum glaucum), em comparação à das temperadas (Avena strigosa e Lolium multiflorum) (Fanti et al., 2008). Além disso, os animais, possivelmente, sofreram com o estresse térmico, uma vez que a temperatura máxima média da região onde se desenvolveu o estudo é de $31,2^{\circ} \mathrm{C}$, o que limita o consumo de matéria seca e diminui o teor de proteína do leite (Fanti et al., 2008). Segundo Vargas et al. (2014), animais em ambientes com temperaturas elevadas apresentam menor capacidade de respostas a doenças, o que aumenta sua suscetibilidade à invasão do úbere por microrganismos e, no presente trabalho, resultou nos maiores valores de CCS no verão (Tabela 3 ).

A elevação do conteúdo de sólidos totais no outono deveu-se, principalmente, à elevação do conteúdo de proteína e gordura do leite.

O aumento da CBT, com a diminuição dos níveis de especialização das UPL (Tabela 3), deveu-se, possivelmente, ao tipo e ao local de ordenha, bem como ao emprego ou não do resfriamento. Assim, o sistema altamente especializado, por possuir sala de ordenha própria, com circuito fechado e tanque de refrigeração a granel (Tabela 1), apresentou os menores valores de CBT.

Houve interação significativa entre os sistemas produtivos e as estações, para todos os ácidos graxos saturados, monoinsaturados e poli-insaturados (Tabelas 4, 5 e 6), bem como para os índices de qualidade da fração lipídica (Tabela 5).

Com a diminuição do grau de especialização dos sistemas produtivos, observou-se menor concentração do somatório dos ácidos graxos saturados ( $\Sigma$ AGS), nas estações primavera, verão e outono (Tabela 4). Isto se atribui à maior participação de forragens frescas (Chilliard et al., 2007) na dieta dos extratos menos especializados.

No inverno, observou-se menor concentração de ácido linoleico $(18: 2 \mathrm{n} 6-\mathrm{c} 9, \mathrm{c} 12)$ e maiores valores de ácido rumênico e do somatório dos ácidos graxos poli-insaturados ( $\Sigma$ AGPI), nos extratos produtivos menos especializados (Tabela 6). Esses resultados estão relacionados ao predomínio de uso dos extratos menos especializados, de pastagens de aveia-preta (Avena strigosa) e azevém (Lolium multiflorum), em detrimento da silagem de milho e de concentrado, o que teria resultado em maiores concentrações de ácido alfa-linolênico $(18: 3 \mathrm{n} 3-\mathrm{c} 9, \mathrm{c} 12, \mathrm{c} 15)$ do que de ácido linoleico e oleico (18:1n9-c9) na dieta (Tabela 2). Conforme Dewhurst et al. (2006), isto aumenta as concentrações de ácido rumênico e $\Sigma$ AGPI e diminui a concentração de ácido linoleico no leite, o que corrobora os resultados obtidos no presente trabalho (Tabela 6).

O extrato produtivo mais especializado, apesar de não ter significativamente diferido dos dois extratos seguintes, aparentemente favoreceu a formação de ácido rumênico, a ponto de seus teores terem-se igualado estatisticamente aos observados no extrato com a menor especialização, que apresentou o maior valor desse ácido graxo (Tabela 6). Assim, podese inferir que a relação volumoso:concentrado, nos três primeiros níveis de especialização, influenciou esse resultado. No sistema produtivo altamente especializado, que utiliza a maior suplementação com concentrado na dieta (Tabela 1), os limites da relação volumoso:concentrado foram comprometidos, o que segundo Chilliard et al. (2007) diminui a 
bio-hidrogenação ruminal dos ácidos graxos de cadeia longa e inibe a etapa final desse processo, em que o ácido transvacênico (18:1n7-t11) é convertido a ácido esteárico (18:0). Assim, após a dessaturação do ácido transvacênico na glândula mamária pela enzima delta(9)-dessaturase, os teores de ácido rumênico no leite aumentam (Tabela 6).

Os extratos altamente especializado e especializado não diferiram quanto aos teores de ácido rumênico; no entanto, nos sistemas semiespecializado e não especializado, os menores valores para esse ácido foram constatados no outono, e os maiores, no inverno e na primavera. Como nos extratos mais especializados o processo de formação desse ácido graxo depende principalmente da concentração de ácido linoleico na dieta, e as fontes dietéticas nesses manejos que o contêm em sua composição (silagem de milho e concentrado) (Tabela 2) não são tão suscetíveis a variações sazonais, não houve variação nos teores de ácido rumênico (CLA, 18:2n7 - c9, t11) entre esses extratos (Tabela 6).

Nos níveis de menor especialização, a formação de ácido rumênico depende da participação do ácido alfa-linolênico, principal constituinte das pastagens frescas na dieta (Tabela 2). Portanto, esses sistemas produtivos são mais suscetíveis a alterações climáticas, com maiores teores do ácido alfa-linolênico nas pastagens temperadas, que são exploradas até a primavera, e menores nas pastagens tropicais. Além disso, a menor disponibilidade forrageira no

Tabela 3. Médiaterro-padrão dos teores de proteína total, gordura, sólidos totais, contagem de células somáticas (CCS) e contagem bacteriana total (CBT) do leite bovino, nos sistemas de produção altamente especializado (AE), especializado (ES), semiespecializado (SE) e não especializado (NE), nas diferentes estações do ano ${ }^{(1)}$.

\begin{tabular}{|c|c|c|c|c|c|}
\hline \multirow[t]{2}{*}{ Sistema } & \multicolumn{4}{|c|}{ Estação do ano } & \multirow[t]{2}{*}{ Média } \\
\hline & Primavera & Verão & Outono & Inverno & \\
\hline & \multicolumn{5}{|c|}{ Proteína total $(\%)$} \\
\hline Altamente especializado & 3,07 & 2,96 & 3,12 & 3,11 & $3,07 \pm 0,09$ \\
\hline Especializado & 3,10 & 3,05 & 3,07 & 3,06 & $3,07 \pm 0,09$ \\
\hline Semiespecializado & 3,28 & 3,18 & 3,17 & 3,20 & $3,21 \pm 0,09$ \\
\hline Não especializado & 3,01 & 2,94 & 3,23 & 3,14 & $3,08 \pm 0,09$ \\
\hline \multirow[t]{2}{*}{ Média } & $3,11 \pm 0,11 \mathrm{a}$ & $3,03 \pm 0,11 \mathrm{~b}$ & $3,15 \pm 0,11 \mathrm{a}$ & $3,13 \pm 0,11 \mathrm{a}$ & - \\
\hline & \multicolumn{5}{|c|}{ Gordura (\%) } \\
\hline Altamente especializado & 3,52 & 3,50 & 3,51 & 3,32 & $3,46 \pm 0,14$ \\
\hline Especializado & 3,67 & 3,96 & 3,37 & 3,57 & $3,64 \pm 0,14$ \\
\hline Semiespecializado & 3,88 & 3,70 & 3,77 & 3,78 & $3,78 \pm 0,14$ \\
\hline Não especializado & 3,74 & 4,03 & 4,03 & 3,62 & $3,86 \pm 0,14$ \\
\hline \multirow[t]{2}{*}{ Média } & $3,70 \pm 0,09$ & $3,80 \pm 0,09$ & $3,67 \pm 0,09$ & $3,57 \pm 0,09$ & - \\
\hline & \multicolumn{5}{|c|}{ Sólidos totais $(\%)$} \\
\hline Altamente especializado & 11,62 & 11,96 & 12,11 & 11,72 & $11,85 \pm 0,22$ \\
\hline Especializado & 11,87 & 12,06 & 11,98 & 11,37 & $11,82 \pm 0,22$ \\
\hline Semiespecializado & 12,36 & 12,61 & 12,23 & 12,22 & $12,36 \pm 0,22$ \\
\hline Não especializado & 11,97 & 12,83 & 13,19 & 11,99 & $12,49 \pm 0,22$ \\
\hline \multirow[t]{2}{*}{ Média } & $11,96 \pm 0,15 b c$ & $12,36 \pm 0,15 \mathrm{ab}$ & $12,38 \pm 0,15 \mathrm{a}$ & $11,83 \pm 0,15 \mathrm{c}$ & - \\
\hline & \multicolumn{5}{|c|}{ Contagem de células somáticas (células $\mathrm{mL}^{-1}$ ) } \\
\hline Altamente especializado & 521,18 & 619,30 & 692,62 & 565,68 & $599,70 \pm 0,36$ \\
\hline Especializado & 415,11 & 882,78 & 504,32 & 516,38 & $579,65 \pm 0,36$ \\
\hline Semiespecializado & 517,34 & 554,23 & 630,30 & 455,25 & $539,28 \pm 0,36$ \\
\hline Não especializado & 324,26 & 539,38 & 503,03 & 357,40 & $431,02 \pm 0,36$ \\
\hline \multirow[t]{2}{*}{ Média } & $444,47 \pm 0,20 \mathrm{~b}$ & $648,92 \pm 0,20 \mathrm{a}$ & $582,57 \pm 0,20 \mathrm{ab}$ & $473,67 \pm 0,20 \mathrm{~b}$ & - \\
\hline & \multicolumn{5}{|c|}{ Contagem bacteriana total (unidades formadoras de colônia $\mathrm{mL}^{-1}$ ) } \\
\hline Altamente especializado & 211,33 & 209,86 & 155,73 & 239,09 & $204,00 \pm 0,05 \mathrm{~B}$ \\
\hline Especializado & 229,50 & 201,98 & 202,64 & 245,26 & $219,83 \pm 0,05 \mathrm{AB}$ \\
\hline Semiespecializado & 235,23 & 211,09 & 263,86 & 292,21 & $250,60 \pm 0,05 \mathrm{~A}$ \\
\hline Não especializado & 252,70 & 229,54 & 240,71 & 220,15 & $235,77 \pm 0,05 \mathrm{~A}$ \\
\hline Média & $232,18 \pm 0,09$ & $213,12 \pm 0,09$ & $215,73 \pm 0,09$ & $249,18 \pm 0,09$ & - \\
\hline
\end{tabular}

${ }^{(1)}$ Médias seguidas por letras iguais, minúsculas nas colunas e maiúsculas nas linhas, não diferem pelo teste Tukey, a 5\% de probabilidade. 
Tabela 4. Média \pm erro-padrão dos teores de ácidos graxos $\left(\mathrm{mg} \mathrm{g}^{-1}\right)$ saturados e somatório dos ácidos graxos saturados ( $\Sigma$ AGS) no leite bovino, nos sistemas de produção altamente especializado (AE), especializado (ES), semiespecializado (SE) e não especializado (NE), nas diferentes estações do ano ${ }^{(1)}$.

\begin{tabular}{|c|c|c|c|c|c|}
\hline \multirow[t]{2}{*}{ Sistema } & \multicolumn{4}{|c|}{ Estação do ano } & \multirow[t]{2}{*}{ Média } \\
\hline & Primavera & Verão & Outono & Inverno & \\
\hline & & & 4:0 (ácido butíri & & \\
\hline Altamente especializado & $35,36 \mathrm{Aa}$ & $33,13 \mathrm{Ba}$ & $35,58 \mathrm{Aa}$ & $29,61 \mathrm{Aa}$ & $33,42 \pm 0,89$ \\
\hline Especializado & $40,94 \mathrm{Aa}$ & $37,58 \mathrm{Aba}$ & $37,22 \mathrm{Aa}$ & $36,03 \mathrm{Aa}$ & $37,94 \pm 0,89$ \\
\hline Semiespecializado & $39,54 \mathrm{Aa}$ & $35,51 \mathrm{Ba}$ & $37,64 \mathrm{Aa}$ & $34,62 \mathrm{Aa}$ & $36,83 \pm 0,89$ \\
\hline Não especializado & $33,18 \mathrm{Ab}$ & $43,05 \mathrm{Aa}$ & $35,02 \mathrm{Aab}$ & $36,25 \mathrm{Aab}$ & $36,88 \pm 0,89$ \\
\hline \multirow[t]{2}{*}{ Média } & $37,26 \pm 1,01$ & $37,32 \pm 0,61$ & $36,37 \pm 0,98$ & $34,13 \pm 1,01$ & - \\
\hline & & & 6:0 (ácido caprol & & \\
\hline Altamente especializado & $12,37 \mathrm{ABa}$ & $12,80 \mathrm{Aa}$ & $13,34 \mathrm{Aa}$ & $11,87 \mathrm{Aa}$ & $12,59 \pm 0,35$ \\
\hline Especializado & $13,56 \mathrm{Aa}$ & $13,82 \mathrm{Aa}$ & $11,78 \mathrm{Aa}$ & $12,01 \mathrm{Aa}$ & $12,79 \pm 0,35$ \\
\hline Semiespecializado & $13,42 \mathrm{Aa}$ & $12,19 \mathrm{Aa}$ & $11,06 \mathrm{Aa}$ & $12,11 \mathrm{Aa}$ & $12,20 \pm 0,35$ \\
\hline Não especializado & $10,12 \mathrm{Ba}$ & $13,25 \mathrm{Aa}$ & $11,19 \mathrm{Aa}$ & $11,20 \mathrm{Aa}$ & $11,44 \pm 0,35$ \\
\hline \multirow[t]{2}{*}{ Média } & $12,37 \pm 0,29$ & $13,02 \pm 0,34$ & $11,84 \pm 0,27$ & $11,80 \pm 0,40$ & - \\
\hline & & & 8:0 (ácido capríl & & \\
\hline Altamente especializado & 7,93Aa & $8,52 \mathrm{Aa}$ & $8,41 \mathrm{Aa}$ & 7,64Aa & $8,12 \pm 0,19$ \\
\hline Especializado & 8,31Aab & $9,21 \mathrm{Aa}$ & 8,91Aa & $6,41 \mathrm{Ab}$ & $8,21 \pm 0,19$ \\
\hline Semiespecializado & $7,72 \mathrm{ABa}$ & $8,43 \mathrm{Aa}$ & $8,32 \mathrm{ABa}$ & 7,63Aa & $8,02 \pm 0,19$ \\
\hline Não especializado & $5,43 \mathrm{Bb}$ & 7,90Aa & $6,52 \mathrm{Bab}$ & 6,57Aab & $6,60 \pm 0,19$ \\
\hline \multirow[t]{2}{*}{ Média } & $7,34 \pm 0,22$ & $8,51 \pm 0,15$ & $8,04 \pm 0,18$ & $7,06 \pm 0,16$ & - \\
\hline & & & 10:0 (ácido cápri & & \\
\hline Altamente especializado & $18,76 \mathrm{Aa}$ & $17,60 \mathrm{Aa}$ & $18,92 \mathrm{Aa}$ & $19,17 \mathrm{Aa}$ & $18,61 \pm 0,38$ \\
\hline Especializado & $17,52 \mathrm{Aab}$ & $19,00 \mathrm{Aa}$ & $15,96 \mathrm{ABab}$ & $14,08 \mathrm{Ab}$ & $16,64 \pm 0,38$ \\
\hline Semiespecializado & $17,46 \mathrm{Aa}$ & $16,99 \mathrm{Aa}$ & $14,58 \mathrm{Ba}$ & $17,37 \mathrm{Aa}$ & $16,60 \pm 0,38$ \\
\hline Não especializado & $12,56 \mathrm{Bb}$ & $15,70 \mathrm{Aab}$ & $17,38 \mathrm{ABa}$ & $15,96 \mathrm{Aab}$ & $15,40 \pm 0,38$ \\
\hline \multirow[t]{2}{*}{ Média } & $16,57 \pm 0,31$ & $17,32 \pm 0,38$ & $16,71 \pm 0,36$ & $16,65 \pm 0,50$ & - \\
\hline & & & 12:0 (ácido láuri & & \\
\hline Altamente especializado & $19,27 \mathrm{Aa}$ & $22,16 \mathrm{Aa}$ & $23,11 \mathrm{Aa}$ & 21,11Aa & $21,41 \pm 0,68$ \\
\hline Especializado & $21,78 \mathrm{Aa}$ & $21,08 \mathrm{Aa}$ & $18,86 \mathrm{Aa}$ & 19,14Aa & $20,22 \pm 0,68$ \\
\hline Semiespecializado & $20,03 \mathrm{Aa}$ & $19,62 \mathrm{Aa}$ & $17,85 \mathrm{Aa}$ & $19,63 \mathrm{Aa}$ & $19,28 \pm 0,68$ \\
\hline Não especializado & $11,80 \mathrm{Bb}$ & $18,69 \mathrm{Aa}$ & $16,90 \mathrm{Aab}$ & $17,73 \mathrm{Aa}$ & $16,28 \pm 0,68$ \\
\hline \multirow[t]{2}{*}{ Média } & $18,22 \pm 0,35$ & $20,39 \pm 0,57$ & $19,18 \pm 0,73$ & $19,40 \pm 0,66$ & - \\
\hline & & & 14:0 (ácido mirís & & \\
\hline Altamente especializado & $93,67 \mathrm{Aa}$ & $99,40 \mathrm{Aa}$ & $100,02 \mathrm{Aa}$ & $92,89 \mathrm{Aa}$ & $96,50 \pm 1,93$ \\
\hline Especializado & $91,63 \mathrm{Aa}$ & $96,47 \mathrm{Aa}$ & $96,48 \mathrm{Aa}$ & $87,67 \mathrm{Aa}$ & $93,06 \pm 1,93$ \\
\hline Semiespecializado & $88,62 \mathrm{Aa}$ & $93,63 \mathrm{Aa}$ & $89,83 \mathrm{ABa}$ & $86,45 \mathrm{Aa}$ & $89,63 \pm 1,93$ \\
\hline Não especializado & $64,53 \mathrm{Bb}$ & $87,75 \mathrm{Aa}$ & $78,20 \mathrm{Bab}$ & $84,27 \mathrm{Aa}$ & $78,68 \pm 1,93$ \\
\hline \multirow[t]{2}{*}{ Média } & $84,61 \pm 1,60$ & $94,31 \pm 1,18$ & $91,13 \pm 1,61$ & $87,82 \pm 1,65$ & - \\
\hline & & & 16:0 (ácido palmí & & \\
\hline Altamente especializado & $229,38 \mathrm{Ab}$ & $286,81 \mathrm{Aa}$ & $276,05 \mathrm{Aa}$ & $238,41 \mathrm{Bab}$ & $257,66 \pm 4,45$ \\
\hline Especializado & $278,76 \mathrm{Aab}$ & $297,12 \mathrm{Aa}$ & $252,89 \mathrm{ABb}$ & $313,34 \mathrm{Aa}$ & $285,53 \pm 4,45$ \\
\hline Semiespecializado & $256,98 \mathrm{Aa}$ & 267,19Aba & $236,21 \mathrm{Ba}$ & $230,18 \mathrm{Ba}$ & $247,64 \pm 4,45$ \\
\hline Não especializado & $204,91 \mathrm{Aa}$ & $258,95 \mathrm{Ba}$ & $234,55 \mathrm{Bab}$ & $205,24 \mathrm{Bb}$ & $225,91 \pm 4,45$ \\
\hline \multirow[t]{2}{*}{ Média } & $242,51 \pm 4,97$ & $277,52 \pm 3,88$ & $249,93 \pm 3,27$ & $246,79 \pm 5,32$ & - \\
\hline & & & 18:0 (ácido esteár & & \\
\hline Altamente especializado & $104,72 \mathrm{Ba}$ & $108,39 \mathrm{Ba}$ & $110,43 \mathrm{Aa}$ & $100,78 \mathrm{Aa}$ & $106,08 \pm 2,20$ \\
\hline Especializado & $118,15 \mathrm{ABab}$ & $127,40 \mathrm{Aba}$ & $99,87 \mathrm{Ab}$ & 106,57Aab & $113,00 \pm 2,20$ \\
\hline Semiespecializado & $128,57 \mathrm{Aa}$ & $114,95 \mathrm{Bab}$ & $105,91 \mathrm{Ab}$ & 109,59Aab & $114,75 \pm 2,20$ \\
\hline Não especializado & $127,07 \mathrm{Aa}$ & $141,87 \mathrm{Aa}$ & $95,81 \mathrm{Ab}$ & $122,70 \mathrm{Aab}$ & $121,86 \pm 2,20$ \\
\hline \multirow[t]{2}{*}{ Média } & $119,63 \pm 1,40$ & $123,15 \pm 1,67$ & $103,01 \pm 2,09$ & $109,91 \pm 3,26$ & - \\
\hline & & & 20:0 (ácido araquí & & \\
\hline Altamente especializado & $1,07 \mathrm{Cab}$ & $1,22 \mathrm{Aa}$ & $1,05 \mathrm{Aab}$ & $0,80 \mathrm{Bb}$ & $1,03 \pm 0,05$ \\
\hline Especializado & $1,45 \mathrm{BCa}$ & $1,47 \mathrm{Aa}$ & 0,99Aab & $0,87 \mathrm{Bb}$ & $1,19 \pm 0,05$ \\
\hline Semiespecializado & $2,30 \mathrm{Aa}$ & $1,36 \mathrm{Ab}$ & $1,40 \mathrm{Ab}$ & $0,89 \mathrm{Bc}$ & $1,49 \pm 0,05$ \\
\hline Não especializado & $1,67 \mathrm{Ba}$ & $1,61 \mathrm{Aa}$ & $1,02 \mathrm{Ab}$ & $1,70 \mathrm{Aa}$ & $1,50 \pm 0,05$ \\
\hline \multirow[t]{2}{*}{ Média } & $1,62 \pm 0,05$ & $1,41 \pm 0,04$ & $1,11 \pm 0,06$ & $1,07 \pm 0,03$ & - \\
\hline & & & $\Sigma$ AGS & & \\
\hline Altamente especializado & $538,98 \mathrm{ABa}$ & $610,06 \mathrm{Aba}$ & $611,27 \mathrm{Aa}$ & $536,08 \mathrm{Aa}$ & $574,10 \pm 7,63$ \\
\hline Especializado & $618,31 \mathrm{Aab}$ & $664,28 \mathrm{Aa}$ & $548,41 \mathrm{Bb}$ & $615,99 \mathrm{Aab}$ & $611,74 \pm 7,63$ \\
\hline Semiespecializado & $609,12 \mathrm{Aa}$ & $594,16 \mathrm{Ba}$ & $514,30 \mathrm{Bb}$ & 537,14Aab & $563,68 \pm 7,63$ \\
\hline Não especializado & $496,90 \mathrm{Bb}$ & $632,79 \mathrm{Aba}$ & $503,51 \mathrm{Bb}$ & $514,49 \mathrm{Ab}$ & $536,92 \pm 7,63$ \\
\hline Média & $565,82 \pm 8,62$ & $625,32 \pm 6,13$ & $544,37 \pm 5,36$ & $550,93 \pm 10,04$ & - \\
\hline
\end{tabular}

${ }^{(1)}$ Médias seguidas por letras iguais, minúsculas nas colunas e maiúsculas nas linhas, não diferem pelo teste Tukey, a $5 \%$ de probabilidade. 
Tabela 5. Média \pm erro-padrão dos ácidos graxos $\left(\mathrm{mg} \mathrm{g}^{-1}\right)$ monoinsaturados, somatório dos ácidos graxos monoinsaturados ( $\Sigma$ AGMI), atividade da enzima delta(9)-dessaturase, índice de aterogenicidade, índice de trombogenicidade, razão de ácidos graxos hipocolesterolêmico e hipercolesterolêmico $(\mathrm{h} / \mathrm{H})$, ácidos graxos desejáveis e índice nutracêutico do leite bovino, nos sistemas de produção altamente especializado (AE), especializado (ES), semiespecializado (SE) e não especializado (NE), nas diferentes estações do ano ${ }^{(1)}$.

\begin{tabular}{|c|c|c|c|c|c|}
\hline \multirow[t]{2}{*}{ Sistema } & \multicolumn{4}{|c|}{ Estação do ano } & \multirow[t]{2}{*}{ Média } \\
\hline & Primavera & Verão & Outono & Inverno & \\
\hline & & & c9 (ácido miri & & \\
\hline Altamente especializado & $6,75 \mathrm{Ab}$ & 7,67Aab & $8,40 \mathrm{Aa}$ & 7,45Aab & $7,57 \pm 0,14$ \\
\hline Especializado & $6,70 \mathrm{Aa}$ & $6,13 \mathrm{Aba}$ & $7,05 \mathrm{ABa}$ & $5,19 \mathrm{Ba}$ & $6,27 \pm 0,14$ \\
\hline Semiespecializado & $6,64 \mathrm{Aa}$ & $6,97 \mathrm{Aba}$ & $5,54 \mathrm{Ba}$ & $6,06 \mathrm{ABa}$ & $6,30 \pm 0,14$ \\
\hline Não especializado & $3,31 \mathrm{Bc}$ & $5,59 \mathrm{Bb}$ & $5,51 \mathrm{Bb}$ & $7,65 \mathrm{Aa}$ & $5,52 \pm 0,14$ \\
\hline \multirow[t]{2}{*}{ Média } & $5,85 \pm 0,14$ & $6,59 \pm 0,16$ & $6,63 \pm 0,15$ & $6,59 \pm 0,19$ & - \\
\hline & \multicolumn{5}{|c|}{ 16:1n7-c9 (ácido palmitoleico) } \\
\hline Altamente especializado & $12,71 \mathrm{Aab}$ & $13,72 \mathrm{Aa}$ & $13,73 \mathrm{Aa}$ & $10,42 \mathrm{Ab}$ & $12,64 \pm 0,37$ \\
\hline Especializado & $12,70 \mathrm{Aa}$ & $10,81 \mathrm{Ba}$ & $10,99 \mathrm{ABa}$ & $10,63 \mathrm{Aa}$ & $11,28 \pm 0,37$ \\
\hline Semiespecializado & $12,25 \mathrm{Aab}$ & $12,66 \mathrm{ABa}$ & $9,74 \mathrm{Bb}$ & $9,68 \mathrm{Ab}$ & $11,08 \pm 0,37$ \\
\hline Não especializado & $10,71 \mathrm{Aab}$ & $10,42 \mathrm{Bab}$ & $8,99 \mathrm{Bb}$ & $12,77 \mathrm{Aa}$ & $10,71 \pm 0,37$ \\
\hline \multirow[t]{2}{*}{ Média } & $12,10 \pm 0,29$ & $11,90 \pm 0,25$ & $10,86 \pm 0,29$ & $10,87 \pm 0,29$ & - \\
\hline & \multicolumn{5}{|c|}{ 18:1n9-t9 (ácido elaídico) } \\
\hline Altamente especializado & $3,78 \mathrm{Aab}$ & $3,23 \mathrm{Ab}$ & $3,48 \mathrm{Ab}$ & $4,73 \mathrm{Aa}$ & $3,81 \pm 0,11$ \\
\hline Especializado & $3,87 \mathrm{Aab}$ & $3,55 \mathrm{Aab}$ & $2,91 \mathrm{Ab}$ & $4,35 \mathrm{Ca}$ & $3,67 \pm 0,11$ \\
\hline Semiespecializado & 3,61Aab & $3,35 \mathrm{Ab}$ & $3,16 \mathrm{Ab}$ & $4,44 \mathrm{Aa}$ & $3,64 \pm 0,11$ \\
\hline Não especializado & $4,23 \mathrm{Aa}$ & $3,92 \mathrm{Aa}$ & $2,81 \mathrm{Ab}$ & $3,37 \mathrm{Bab}$ & $3,58 \pm 0,11$ \\
\hline \multirow[t]{2}{*}{ Média } & $3,88 \pm 0,15$ & $3,51 \pm 0,10$ & $3,09 \pm 0,09$ & $4,22 \pm 0,08$ & - \\
\hline & \multicolumn{5}{|c|}{ 18:1n7-t11(ácido transvacênico) } \\
\hline Altamente especializado & $14,14 \mathrm{Bb}$ & $13,24 \mathrm{Bb}$ & $16,97 \mathrm{Aab}$ & $20,41 \mathrm{Aa}$ & $16,19 \pm 0,53$ \\
\hline Especializado & $15,86 \mathrm{ABb}$ & $13,21 \mathrm{Bb}$ & $16,88 \mathrm{Aab}$ & $22,62 \mathrm{Aa}$ & $17,14 \pm 0,53$ \\
\hline Semiespecializado & $18,34 \mathrm{Aa}$ & $18,97 \mathrm{ABa}$ & $16,70 \mathrm{Aa}$ & $20,24 \mathrm{Aa}$ & $18,57 \pm 0,53$ \\
\hline Não especializado & $18,70 \mathrm{Ab}$ & $22,12 \mathrm{Aa}$ & $13,68 \mathrm{Ac}$ & $23,52 \mathrm{Aa}$ & $19,50 \pm 0,53$ \\
\hline Média & $16,76 \pm 0,36$ & $16,89 \pm 0,74$ & $16,06 \pm 0,53$ & $21,70 \pm 0,53$ & - \\
\hline & & & n9-c9 (ácido o & & \\
\hline Altamente especializado & $127,11 \mathrm{Aa}$ & $152,92 \mathrm{Aa}$ & $162,13 \mathrm{Aa}$ & $125,70 \mathrm{Ba}$ & $141,96 \pm 4,95$ \\
\hline Especializado & $145,75 \mathrm{Aa}$ & $154,22 \mathrm{Aa}$ & $135,15 \mathrm{Aa}$ & $126,93 \mathrm{Ba}$ & $140,51 \pm 4,95$ \\
\hline Semiespecializado & $163,06 \mathrm{Aa}$ & $162,80 \mathrm{Aa}$ & $146,65 \mathrm{Aa}$ & $125,38 \mathrm{Ba}$ & $149,47 \pm 4,95$ \\
\hline Não especializado & $138,68 \mathrm{Aab}$ & $157,11 \mathrm{Aab}$ & $126,80 \mathrm{Ab}$ & $176,60 \mathrm{Aa}$ & $149,80 \pm 4,95$ \\
\hline Média & $143,65 \pm 4,07$ & $156,76 \pm 4,91$ & $142,68 \pm 5,32$ & $138,65 \pm 4,39$ & - \\
\hline & & & $\Sigma$ AGMI & & \\
\hline Altamente especializado & $165,43 \mathrm{Aa}$ & $191,48 \mathrm{Aa}$ & $208,33 \mathrm{Aa}$ & $170,73 \mathrm{Ba}$ & $183,99 \pm 5,38$ \\
\hline Especializado & $186,73 \mathrm{Aa}$ & $191,01 \mathrm{Aa}$ & $175,24 \mathrm{Aa}$ & $173,77 \mathrm{Ba}$ & $181,69 \pm 5,38$ \\
\hline Semiespecializado & $209,51 \mathrm{Aa}$ & $203,49 \mathrm{Aa}$ & $186,07 \mathrm{Aa}$ & $169,17 \mathrm{Ba}$ & $192,06 \pm 5,38$ \\
\hline Não especializado & $179,78 \mathrm{Aab}$ & $206,65 \mathrm{Aab}$ & $154,13 \mathrm{Ab}$ & $229,73 \mathrm{Aa}$ & $192,57 \pm 5,38$ \\
\hline Média & $185,36 \pm 4,98$ & $198,16 \pm 5,08$ & $180,94 \pm 5,61$ & $185,85 \pm 5,17$ & - \\
\hline & & & (9)-dessaturas & & \\
\hline Altamente especializado & 6,87Aa & 7,48Aa & $7,54 \mathrm{Aa}$ & $7,33 \mathrm{ABa}$ & $7,30 \pm 0,13$ \\
\hline Especializado & 7,11Aa & $6,49 \mathrm{ABab}$ & $6,51 \mathrm{Aab}$ & $5,48 \mathrm{Bb}$ & $6,40 \pm 0,13$ \\
\hline Semiespecializado & $6,78 \mathrm{Aa}$ & $7,03 \mathrm{ABa}$ & $6,25 \mathrm{Aa}$ & $6,39 \mathrm{Ba}$ & $6,61 \pm 0,13$ \\
\hline Não especializado & $5,32 \mathrm{Ab}$ & $5,87 \mathrm{Bb}$ & $6,30 \mathrm{Ab}$ & $8,38 \mathrm{Aa}$ & $6,47 \pm 0,13$ \\
\hline Média & $6,52 \pm 0,13$ & $6,72 \pm 0,13$ & $6,65 \pm 0,13$ & $6,90 \pm 0,13$ & - \\
\hline & & & e de aterogeni & & \\
\hline Altamente especializado & 3,35Aa & $3,23 \mathrm{Aa}$ & $3,11 \mathrm{ABb}$ & $3,24 \mathrm{Aa}$ & $3,23 \pm 0,11$ \\
\hline Especializado & $3,35 \mathrm{Aa}$ & $3,17 \mathrm{Aa}$ & $3,47 \mathrm{ABa}$ & $3,58 \mathrm{Aa}$ & $3,39 \pm 0,11$ \\
\hline Semiespecializado & $2,91 \mathrm{ABb}$ & $3,12 \mathrm{Aab}$ & $3,77 \mathrm{Aa}$ & $3,16 \mathrm{Aab}$ & $3,24 \pm 0,11$ \\
\hline Não especializado & $2,38 \mathrm{Ba}$ & $2,73 \mathrm{Aa}$ & $2,72 \mathrm{Ba}$ & $2,03 \mathrm{Ba}$ & $2,47 \pm 0,11$ \\
\hline Média & $3,00 \pm 0,08$ & $3,06 \pm 0,06$ & $3,27 \pm 0,10$ & $3,00 \pm 0,07$ & - \\
\hline & & & de trombogen & & \\
\hline Altamente especializado & $4,38 \mathrm{ABa}$ & $4,38 \mathrm{ABa}$ & $4,15 \mathrm{Aa}$ & $4,30 \mathrm{Ba}$ & $4,30 \pm 0,12$ \\
\hline Especializado & $4,57 \mathrm{Aa}$ & $4,57 \mathrm{Aa}$ & $4,76 \mathrm{Aa}$ & $5,13 \mathrm{Aa}$ & $4,76 \pm 0,12$ \\
\hline Semiespecializado & $3,85 \mathrm{ABa}$ & $3,92 \mathrm{ABa}$ & $4,87 \mathrm{Aa}$ & $4,17 \mathrm{Ba}$ & $4,20 \pm 0,12$ \\
\hline Não especializado & $3,69 \mathrm{Bab}$ & $4,06 \mathrm{Ba}$ & $4,38 \mathrm{Aa}$ & $3,10 \mathrm{Cb}$ & $3,81 \pm 0,12$ \\
\hline Média & $4,12 \pm 0,08$ & $4,23 \pm 0,08$ & $4,54 \pm 0,14$ & $4,17 \pm 0,08$ & - \\
\hline & & Razão de ácid & olesterolêmic & rolêmico $(\mathrm{h} / \mathrm{H})$ & \\
\hline Altamente especializado & $0,46 \mathrm{Ba}$ & $0,44 \mathrm{Aa}$ & $0,47 \mathrm{Aa}$ & $0,45 \mathrm{Ba}$ & $0,45 \pm 0,03$ \\
\hline Especializado & $0,45 \mathrm{Ba}$ & $0,44 \mathrm{Aa}$ & $0,41 \mathrm{Aa}$ & $0,40 \mathrm{Ba}$ & $0,43 \pm 0,03$ \\
\hline Semiespecializado & $0,53 \mathrm{ABa}$ & $0,49 \mathrm{Aa}$ & $0,47 \mathrm{Aa}$ & $0,47 \mathrm{Ba}$ & $0,49 \pm 0,03$ \\
\hline Não especializado & $0,63 \mathrm{Aa}$ & $0,51 \mathrm{Ab}$ & $0,46 \mathrm{Ab}$ & $0,64 \mathrm{Aa}$ & $0,56 \pm 0,03$ \\
\hline Média & $0,52 \pm 0,01$ & $0,47 \pm 0,01$ & $0,45 \pm 0,01$ & $0,49 \pm 0,01$ & - \\
\hline & & & os graxos dese & & \\
\hline Altamente especializado & $300,38 \mathrm{Aa}$ & $323,80 \mathrm{Aa}$ & $337,80 \mathrm{Aa}$ & $312,37 \mathrm{Aa}$ & $318,59 \pm 6,92$ \\
\hline Especializado & $339,94 \mathrm{Aa}$ & $320,04 \mathrm{Aa}$ & $315,60 \mathrm{Aa}$ & $310,40 \mathrm{Aa}$ & $321,49 \pm 6,92$ \\
\hline Semiespecializado & $346,99 \mathrm{Aa}$ & $349,36 \mathrm{Aa}$ & $315,60 \mathrm{Aa}$ & $304,91 \mathrm{Aa}$ & $330,48 \pm 6,92$ \\
\hline Não especializado & $354,78 \mathrm{Aab}$ & $355,44 \mathrm{Aab}$ & $298,55 \mathrm{Ab}$ & $375,86 \mathrm{Aa}$ & $346,16 \pm 6,92$ \\
\hline Média & $335,52 \pm 7,09$ & $337,16 \pm 4,81$ & $318,15 \pm 6,75$ & $325,88 \pm 6,86$ & - \\
\hline & & & dice nutracêut & & \\
\hline Altamente especializado & $4,87 \mathrm{Aab}$ & $2,28 \mathrm{Bb}$ & $4,14 \mathrm{Aab}$ & $6,59 \mathrm{Ba}$ & $4,47 \pm 0,48$ \\
\hline Especializado & $4,14 \mathrm{Aab}$ & $4,07 \mathrm{Bb}$ & $4,04 \mathrm{Ab}$ & $7,13 \mathrm{ABa}$ & $4,85 \pm 0,48$ \\
\hline Semiespecializado & $7,32 \mathrm{Aa}$ & $6,10 \mathrm{ABa}$ & $3,64 \mathrm{Ba}$ & $8,04 \mathrm{ABa}$ & $6,27 \pm 0,48$ \\
\hline Não especializado & $7,11 \mathrm{Ab}$ & $9,74 \mathrm{Ab}$ & $4,68 \mathrm{Ab}$ & $12,36 \mathrm{Aa}$ & $8,47 \pm 0,48$ \\
\hline Média & $5,86 \pm 0,52$ & $5,55 \pm 0,39$ & $4,12 \pm 0,51$ & $8,53 \pm 0,51$ & - \\
\hline
\end{tabular}

${ }^{(1)}$ Médias seguidas por letras iguais, minúsculas nas colunas e maiúsculas nas linhas, não diferem pelo teste Tukey, a 5\% de probabilidade. 
Tabela 6. Média \pm erro-padrão ajustadas dos ácidos graxos $\left(\mathrm{mg} \mathrm{g}^{-1}\right)$ poli-insaturados, somatório dos ácidos graxos ômega 3 ( $(\mathrm{n} 3)$, dos ácidos graxos ômega $6(\Sigma \mathrm{n} 6)$, da relação ômega 6 e ômega $3(\Sigma$ n6:n3) e do total de ácidos graxos poli-insaturados $(\Sigma \mathrm{AGPI})$ do leite bovino, nos sistemas produtivos altamente especializado (AE), especializado (ES), semiespecializado (SE) e não especializado (NE), nas distintas estações do ano ${ }^{(1)}$.

\begin{tabular}{|c|c|c|c|c|c|}
\hline \multirow[t]{2}{*}{ Sistema } & \multicolumn{4}{|c|}{ Estação do ano } & \multirow[t]{2}{*}{ Média } \\
\hline & Primavera & Verão & Outono & Inverno & \\
\hline & \multicolumn{5}{|c|}{ 18:2n6-c9,c12 (ácido linoleico) } \\
\hline Altamente especializado & $12,19 \mathrm{Aa}$ & $11,49 \mathrm{Aa}$ & $11,85 \mathrm{Aa}$ & 9,96Аа & $11,37 \pm 0,26$ \\
\hline Especializado & $13,91 \mathrm{Aa}$ & $9,97 \mathrm{Ab}$ & $9,93 \mathrm{Ab}$ & $10,46 \mathrm{Ab}$ & $11,07 \pm 0,26$ \\
\hline Semiespecializado & $10,71 \mathrm{Ba}$ & $10,45 \mathrm{Aa}$ & 9,97Aa & $9,28 \mathrm{ABa}$ & $10,10 \pm 0,26$ \\
\hline Não especializado & $9,91 \mathrm{Ba}$ & $8,50 \mathrm{Ba}$ & $7,73 \mathrm{Ba}$ & $7,70 \mathrm{Ba}$ & $8,46 \pm 0,26$ \\
\hline \multirow[t]{2}{*}{ Média } & $11,68 \pm 0,29$ & $10,10 \pm 0,16$ & $9,87 \pm 0,25$ & $9,35 \pm 0,32$ & - \\
\hline & \multicolumn{5}{|c|}{ 18:3n3-c9,c12,c15 (ácido $\alpha$-linolênico-AAL) } \\
\hline Altamente especializado & $2,46 \mathrm{Aab}$ & $1,66 \mathrm{Bb}$ & $1,73 \mathrm{Bb}$ & $3,11 \mathrm{Aa}$ & $2,31 \pm 0,08$ \\
\hline Especializado & 2,73Aab & $1,81 \mathrm{Bb}$ & $2,14 \mathrm{Ab}$ & $3,05 \mathrm{Aa}$ & $2,43 \pm 0,08$ \\
\hline Semiespecializado & 3,09Aa & $3,13 \mathrm{Aa}$ & $1,60 \mathrm{Bb}$ & 3,37Aa & $2,80 \pm 0,08$ \\
\hline Não especializado & $3,04 \mathrm{Aa}$ & $2,73 \mathrm{Aa}$ & $1,81 \mathrm{ABb}$ & 3,38Aa & $2,67 \pm 0,08$ \\
\hline \multirow[t]{2}{*}{ Média } & $2,83 \pm 0,10$ & $2,33 \pm 0,07$ & $1,82 \pm 0,04$ & $3,23 \pm 0,10$ & - \\
\hline & \multicolumn{5}{|c|}{ 18:2n7- c9,t11 (ácido rumênico-CLA) } \\
\hline Altamente especializado & $6,60 \mathrm{Aa}$ & $5,33 \mathrm{Aa}$ & $6,39 \mathrm{Aa}$ & $7,40 \mathrm{ABa}$ & $6,43 \pm 0,20$ \\
\hline Especializado & $5,97 \mathrm{Aa}$ & $6,38 \mathrm{Aa}$ & $5,58 \mathrm{Aa}$ & $7,20 \mathrm{Ba}$ & $6,28 \pm 0,20$ \\
\hline Semiespecializado & 7,11Aa & $5,16 \mathrm{Ab}$ & $5,65 \mathrm{Aab}$ & $6,71 \mathrm{Bab}$ & $6,16 \pm 0,20$ \\
\hline Não especializado & $7,34 \mathrm{Ab}$ & $5,78 \mathrm{Abc}$ & $4,87 \mathrm{Ac}$ & $10,00 \mathrm{Aa}$ & $7,00 \pm 0,20$ \\
\hline \multirow[t]{2}{*}{ Média } & $6,76 \pm 0,17$ & $5,66 \pm 0,18$ & $5,62 \pm 0,18$ & $7,83 \pm 0,26$ & - \\
\hline & \multicolumn{5}{|c|}{ 18:2n6-t10,c12 (ácido t10,c12-octadecadienoico-CLA) } \\
\hline Altamente especializado & $0,21 \mathrm{Ba}$ & $0,30 \mathrm{Aa}$ & $0,28 \mathrm{Aa}$ & $0,23 \mathrm{Ca}$ & $0,26 \pm 0,01$ \\
\hline Especializado & $0,30 \mathrm{Bab}$ & $0,36 \mathrm{Aa}$ & $0,24 \mathrm{Ab}$ & $0,37 \mathrm{Ba}$ & $0,32 \pm 0,01$ \\
\hline Semiespecializado & $0,31 \mathrm{Bab}$ & $0,31 \mathrm{Aab}$ & $0,28 \mathrm{Ab}$ & $0,37 \mathrm{Ba}$ & $0,32 \pm 0,01$ \\
\hline Não especializado & $0,55 \mathrm{Ab}$ & $0,36 \mathrm{Ac}$ & $0,22 \mathrm{Ad}$ & $0,73 \mathrm{Aa}$ & $0,46 \pm 0,01$ \\
\hline \multirow{2}{*}{ Média } & $0,34 \pm 0,01$ & $0,33 \pm 0,01$ & $0,26 \pm 0,01$ & $0,43 \pm 0,01$ & - \\
\hline & \multicolumn{5}{|c|}{ 20:4n6-c5,c8,c11,c14 (ácido araquidônico-AA) } \\
\hline Altamente especializado & $0,69 \mathrm{ABa}$ & $0,80 \mathrm{Aa}$ & $0,81 \mathrm{Aa}$ & $0,66 \mathrm{Aa}$ & $0,74 \pm 0,02$ \\
\hline Especializado & $0,83 \mathrm{Aa}$ & $0,82 \mathrm{Aa}$ & $0,65 \mathrm{Aa}$ & $0,64 \mathrm{Aa}$ & $0,73 \pm 0,02$ \\
\hline Semiespecializado & $0,66 \mathrm{ABa}$ & $0,68 \mathrm{ABa}$ & $0,68 \mathrm{Aa}$ & $0,56 \mathrm{Aa}$ & $0,64 \pm 0,02$ \\
\hline Não especializado & $0,58 \mathrm{Ba}$ & $0,57 \mathrm{Ba}$ & $0,44 \mathrm{Ba}$ & $0,64 \mathrm{Aa}$ & $0,56 \pm 0,02$ \\
\hline \multirow[t]{2}{*}{ Média } & $0,69 \pm 0,02$ & $0,72 \pm 0,02$ & $0,65 \pm 0,02$ & $0,63 \pm 0,02$ & - \\
\hline & \multicolumn{5}{|c|}{ 20:5n3-c5,c8,c11,c14,c17 (ácido timnodônico-EPA) } \\
\hline Altamente especializado & $0,34 \mathrm{Aab}$ & $0,34 \mathrm{Cab}$ & $0,41 \mathrm{Aa}$ & $0,28 \mathrm{Bb}$ & $0,34 \pm 0,01$ \\
\hline Especializado & $0,21 \mathrm{Bb}$ & $0,38 \mathrm{BCa}$ & $0,24 \mathrm{Bb}$ & $0,30 \mathrm{Bab}$ & $0,28 \pm 0,01$ \\
\hline Semiespecializado & $0,15 \mathrm{Bc}$ & $0,47 \mathrm{Ba}$ & $0,27 \mathrm{Bb}$ & $0,38 \mathrm{Bab}$ & $0,32 \pm 0,01$ \\
\hline Não especializado & $0,26 \mathrm{ABc}$ & $0,75 \mathrm{Aa}$ & $0,41 \mathrm{Ab}$ & $0,68 \mathrm{Aa}$ & $0,52 \pm 0,01$ \\
\hline \multirow[t]{2}{*}{ Média } & $0,24 \pm 0,01$ & $0,48 \pm 0,01$ & $0,33 \pm 0,01$ & $0,41 \pm 0,01$ & - \\
\hline & & & $\Sigma \mathrm{n} 3$ & & \\
\hline Altamente especializado & $2,72 \mathrm{Aa}$ & $2,35 \mathrm{Aa}$ & $3,02 \mathrm{Aa}$ & $3,21 \mathrm{Aa}$ & $2,83 \pm 0,08$ \\
\hline Especializado & $2,94 \mathrm{Aa}$ & $3,24 \mathrm{Aa}$ & 2,14Aa & 3,36Aa & $2,92 \pm 0,08$ \\
\hline Semiespecializado & $3,18 \mathrm{Aa}$ & $2,40 \mathrm{Aa}$ & $2,27 \mathrm{Aa}$ & $3,51 \mathrm{Aa}$ & $2,84 \pm 0,08$ \\
\hline Não especializado & $3,36 \mathrm{Aab}$ & $2,94 \mathrm{Aab}$ & $2,30 \mathrm{Ab}$ & $3,80 \mathrm{Aa}$ & $3,10 \pm 0,08$ \\
\hline Média & $3,05 \pm 0,11$ & $2,73 \pm 0,11$ & $2,43 \pm 0,09$ & $3,47 \pm 0,16$ & - \\
\hline & & & $\sum \mathrm{n} 6$ & & \\
\hline Altamente especializado & $14,85 \mathrm{ABa}$ & $14,65 \mathrm{Aa}$ & $14,54 \mathrm{Aa}$ & $12,57 \mathrm{Aa}$ & $14,15 \pm 0,28$ \\
\hline Especializado & $17,43 \mathrm{Aa}$ & $13,65 \mathrm{ABb}$ & $12,98 \mathrm{Ab}$ & $13,38 \mathrm{Ab}$ & $14,36 \pm 0,28$ \\
\hline Semiespecializado & $14,00 \mathrm{ABa}$ & $12,56 \mathrm{ABa}$ & $13,31 \mathrm{Aa}$ & $11,80 \mathrm{Aa}$ & $12,92 \pm 0,28$ \\
\hline Não especializado & $12,62 \mathrm{Ba}$ & $11,41 \mathrm{Ba}$ & $9,96 \mathrm{Ba}$ & $10,31 \mathrm{Ba}$ & $11,07 \pm 0,28$ \\
\hline Média & $14,72 \pm 0,33$ & $13,07 \pm 0,22$ & $12,70 \pm 0,25$ & $12,02 \pm 0,30$ & - \\
\hline & & & $\Sigma \mathrm{n} 6: \mathrm{n} 3$ & & \\
\hline Altamente especializado & $4,27 \mathrm{Ab}$ & 7,49Aa & $6,68 \mathrm{Aa}$ & $4,35 \mathrm{Ab}$ & $5,70 \pm 0,14$ \\
\hline Especializado & $4,94 \mathrm{Aa}$ & $3,77 \mathrm{Ca}$ & $5,25 \mathrm{Ba}$ & $4,40 \mathrm{Aa}$ & $4,59 \pm 0,14$ \\
\hline Semiespecializado & $3,33 \mathrm{Ab}$ & $5,74 \mathrm{Ba}$ & 7,04Aa & $3,56 \mathrm{Ab}$ & $4,92 \pm 0,14$ \\
\hline Não especializado & $3,06 \mathrm{Aa}$ & $3,42 \mathrm{Ca}$ & $4,24 \mathrm{Ba}$ & $3,40 \mathrm{Aa}$ & $3,53 \pm 0,14$ \\
\hline Média & $3,90 \pm 0,17$ & $5,10 \pm 0,14$ & $5,80 \pm 0,13$ & $3,93 \pm 0,12$ & - \\
\hline & & & $\Sigma$ AGPI & & \\
\hline Altamente especializado & $25,09 \mathrm{Aa}$ & $22,15 \mathrm{Aa}$ & $25,52 \mathrm{Aa}$ & $25,02 \mathrm{ABa}$ & $24,44 \pm 0,43$ \\
\hline Especializado & $25,81 \mathrm{Aa}$ & $23,00 \mathrm{Aab}$ & $21,47 \mathrm{ABb}$ & $25,44 \mathrm{ABab}$ & $23,93 \pm 0,43$ \\
\hline Semiespecializado & $24,96 \mathrm{Aa}$ & $21,94 \mathrm{Aa}$ & $21,40 \mathrm{ABa}$ & $22,55 \mathrm{Ba}$ & $22,71 \pm 0,43$ \\
\hline Não especializado & $23,41 \mathrm{Aa}$ & $24,49 \mathrm{Aa}$ & $17,40 \mathrm{Ba}$ & $27,40 \mathrm{Aa}$ & $23,17 \pm 0,43$ \\
\hline Média & $24,82 \pm 0,45$ & $22,90 \pm 0,49$ & $21,45 \pm 0,45$ & $25,10 \pm 0,42$ & - \\
\hline
\end{tabular}


outono resulta em menores níveis dietéticos de ácido alfa-linolênico, com reflexo no conteúdo do ácido rumênico no leite (Tabela 6).

Portanto, os extratos produtivos altamente especializado e não especializado apresentam características importantes para o aumento do potencial nutracêutico do leite, uma vez que o ácido linoleico conjugado (CLA) está relacionado à redução de uma série de doenças degenerativas, como aterosclerose, à prevenção e tratamento do diabetes mellitus, além de apresentar efeito anticarcinogênico, ser estimulante do sistema imunológico, reduzir a pressão arterial e atuar no metabolismo lipídico corporal, especialmente na redução da gordura corporal e no aumento da massa magra (Kratz et al., 2013; Lahlou et al., 2014). No entanto, o principal antecessor metabólico do ácido rumênico em ruminantes, o ácido transvacênico, por sua conformação geométrica (trans) poderia exercer ação prejudicial à saúde; contudo, Haug et al. (2007) constataram que, em humanos, este ácido graxo pode ser convertido ao seu sucessor.

As principais diferenças observadas no presente estudo estão relacionadas ao comportamento do ácido linoleico e do ácido alfa-linolênico nos diferentes sistemas de produção e estações do ano. As alterações observadas quanto aos conteúdos destes ácidos graxos no leite estão ligadas a modificações no conteúdo de seus sucessores - respectivamente o ácido araquidônico (20:4n6-c5,c8,c11,c14) e o timnodônico (20:5n3-c5,c8,c11,c14,c17) (Tabela 6). De acordo com Simopoulos (2006), a ação de enzimas dessaturases e elongases converte os sucessores em seus respectivos derivados. Entretanto, é importante ressaltar que essas duas famílias de ácidos graxos competem pelas mesmas enzimas envolvidas na dessaturação e no alongamento de suas cadeias (Simopoulos, 2006). Assim, conforme

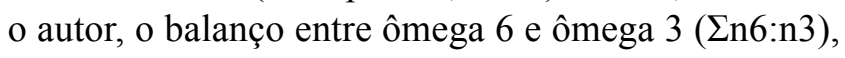
na dieta, assume grande importância na nutrição humana, tendo-se preconizado a diminuição dessa relação.

Os valores de $\Sigma$ n6:n3 diminuíram à medida que a especialização dos sistemas produtivos também diminuiu (Tabela 5). Como Simopoulos (2006) preconiza $\Sigma$ n6:n3 de 2:1 a 4:1, os melhores resultados foram obtidos no sistema não especializado.

O perfil de ácidos graxos mais apropriado para a alimentação humana foi obtido com a diminuição da especialização dos sistemas produtivos e nas estações com maior participação de gramíneas temperadas, ou seja, no inverno e na primavera. Assim, o nível não especializado, no inverno, apresentou o melhor índice nutracêutico do estudo (Tabela 5), pois, além de apresentar maior participação de forrageiras frescas na dieta, o perfil de ácidos graxos nas pastagens temperadas (Tabela 2) favorece a formação dos ácidos transvacênico, rumênico e do ácido t10,c12-octadecadienoico, além de diminuir a $\Sigma$ n6:n3 no leite (Roy et al., 2006; Chilliard et al., 2007).

$\mathrm{O}$ índice nutracêutico proposto mostrou maior poder de diferenciação entre os sistemas de produção, pois as diferenças no índice acentuaram-se entre os extratos mais e menos especializados, principalmente nas estações verão e inverno (Tabela 5). Assim, em estudos de manipulação da dieta que visem à obtenção de um perfil de ácidos graxos mais adequado para o leite de consumo, sugere-se o índice nutracêutico como parâmetro de avaliação da qualidade da fração lipídica do leite.

Além disso, o índice nutracêutico pode ser considerado adequado para analisar a capacidade do leite de contribuir na prevenção e combate de doenças cardiovasculares, uma vez que o nutracêutico apresentou correspondência inversa com os índices de aterogenecidade e trombogenicidade, propostos por Ulbricht \& Southgate (1991), e relação direta com a razão entre ácidos graxos hipocolesterolêmico e hipercolesterolêmico (Santos-Silva et al., 2002) (Tabela 5). O índice também se mostrou mais eficiente na avaliação do potencial nutracêutico do leite do que o conteúdo de ácidos graxos desejáveis (Costa et al., 2008), que não apresentou correspondência com os índices estudados no presente trabalho.

Com a análise de variância multivariada, verificouse diferença significativa entre os vetores de médias, para as diferentes combinações de sistemas produtivos e estações do ano, tanto pelo teste de Wilks, quanto pelos testes Pillai, Hotelling-Lawley e Roy. Os três primeiros autovalores foram significativos pelo teste da razão de verossimilhança; o primeiro autovalor explicou $70,72 \%$, e o segundo, $15,51 \%$, ou seja, os dois primeiros autovalores explicaram $86,23 \%$ da variação total dos dados relacionados ao potencial nutracêutico do leite bovino (Figura 1). Portanto, a análise de componentes principais permitiu visualizar a similaridade e dissimilaridade entre as diferentes combinações entre sistemas produtivos e estações. 
Asvariáveis $\Sigma$ AGPI( $\mathrm{r}=0,69, \mathrm{p}<0,01), \Sigma \mathrm{AGMI}(\mathrm{r}=0,78$, $\mathrm{p}<0,001), \Sigma \mathrm{n} 6: \mathrm{n} 3(\mathrm{r}=-0,74, \mathrm{p}<0,01)$, ácido rumênico $(\mathrm{r}=0,97, \mathrm{p}<0,001)$ e ácido t10,c12-octadecadienoico $(\mathrm{r}=0,93, \mathrm{p}<0,001)$ explicaram a variabilidade do CP1 (componente principal 1), ao passo que as variáveis $\Sigma \mathrm{n} 6: \mathrm{n} 3(\mathrm{r}=0,55, \mathrm{p}<0,05)$ e $\Sigma$ AGPI $(\mathrm{r}=0,58, \mathrm{p}<0,05)$ explicaram a variabilidade do CP2 (Figura 1). A partir das correlações dos componentes principais com as variáveis, pode-se observar que quanto mais à direita (variação explicada pelo CP1) e acima (variação explicada pelo (P2) as combinações se localizarem no plano cartesiano, maior será o potencial nutracêutico do leite, uma vez que essas posições apresentam valores mais elevados de $\Sigma$ AGPI, $\Sigma$ AGMI, ácido rumênico e ácido t10,c12-octadecadienoico, e menores de $\Sigma$ n6:n3; exceto pela variação explicada pelo $\mathrm{CP} 2$ em relação ao $\Sigma$ n6:n3, que apresentou maiores valores em posições mais elevadas.

A análise de agrupamento mostrou que foi quatro o número ideal de grupos formados entre as 16 possíveis combinações entre sistemas produtivos e estações do ano, em que: o grupo I englobou a classe inverno-não especializado; o grupo II, as classes primavera-semiespecializado, primavera-não especializado, verão-semiespecializado, verão-não especializado, inverno-altamente especializado, inverno-especializado e inverno-semiespecializado; o grupo III, as classes primavera-altamente especializado, primavera-especializado, verão-altamente especializado, verão-especializado e outono-altamente

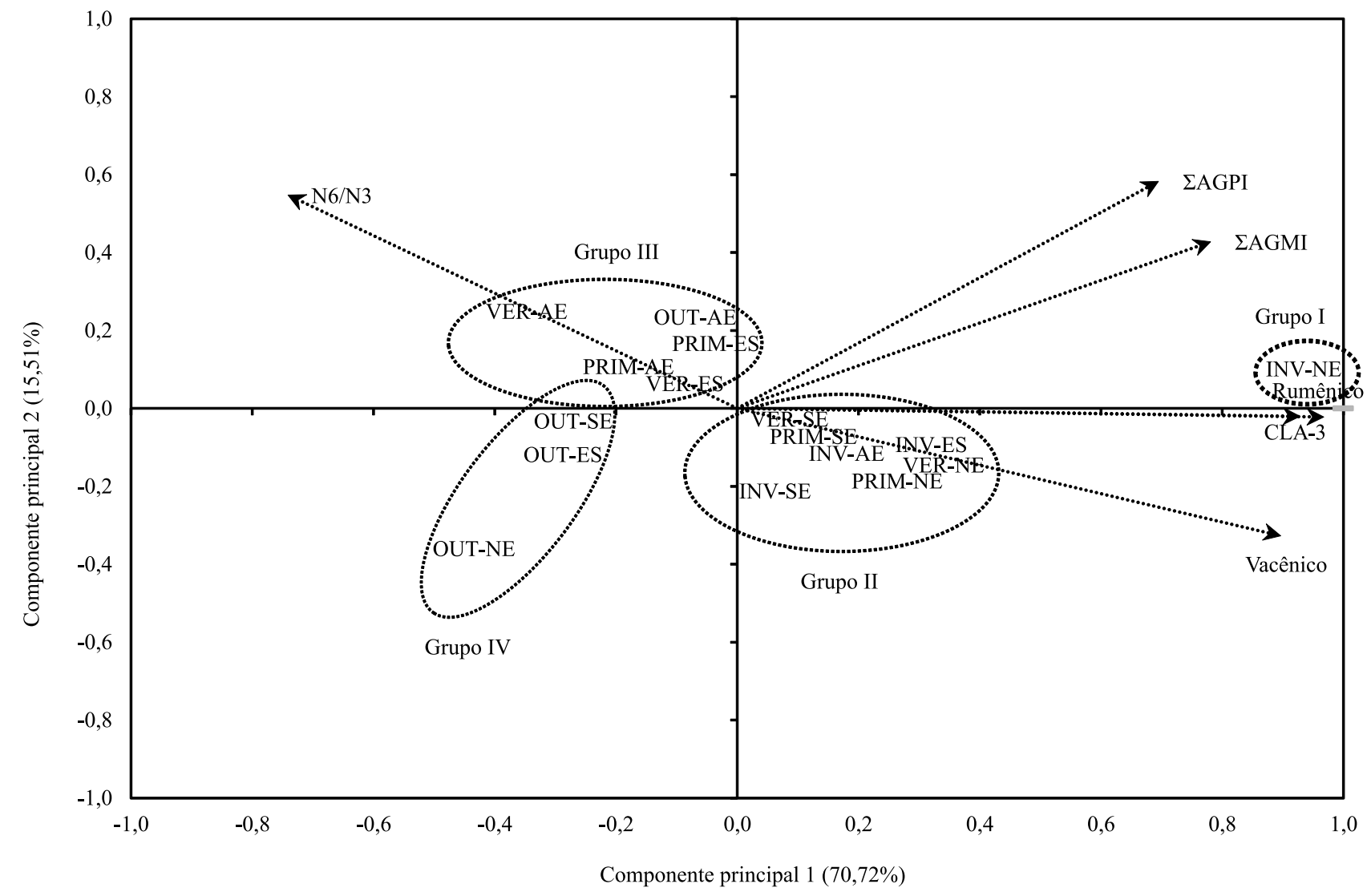

Figura 1. Projeção bidimensional dos escores das diferentes combinações entre os sistemas de produção - altamente especializado (AE), especializado (ES), semiespecializado (SE) e não especializado (NE) - e as diferentes estações do ano - primavera (PRIM), verão (VER), outono (OUT) e inverno (INV), além das cargas (correlações entre as variáveis e os componentes principais) das variáveis: ácido vacênico, total de ácidos graxos monoinsaturados ( $\mathrm{AGMI}$ ), poli-insaturados ( AGPI), relação dos ácidos graxos ômega 6 e ômega 3 (N6/N3) e os isômeros de ácido linoleico conjugado (CLA), ácido rumênico e ácido t10,c12-octadecadienoico (18:2n6-t10,c12). 
especializado; e o grupo IV, as classes outono-especializado, outono-semiespecializado e outono-não especializado (Figura 1).

Portanto, no outono, todos os sistemas produtivos situaram-se no grupo IV, exceto o altamente especializado, que se localizou no grupo III; esse extrato produtivo foi o único capaz de mitigar os efeitos negativos da carência de forragens no outono sobre a qualidade da fração lipídica do leite, o que culminou com um aumento de $\Sigma$ AGPI, $\Sigma$ AGMI, ácido rumênico e ácido t10,c12-octadecadienoico, variação esta explicada pelo CP1 (Figura 1).

Entretanto, é importante ressaltar que, por meio da análise das variáveis que explicaram a variabilidade do CP2, observou-se aumento na $\Sigma$ n6:n3 no nível altamente especializado, no outono, em comparação aos outros sistemas produtivos. Isto se atribui, segundo Chilliard et al. (2007), ao incremento do fornecimento de fontes dietéticas com elevados teores de ácido linoleico, como a silagem de milho e o concentrado (Tabela 2), o que elevaria a absorção intacta desse principal representante da família ômega 6 no leite (Figura 1).

Além da combinação outono-altamente especializado, outras quatro assentaram-se no grupo III, compostas pelos sistemas produtivos altamente especializado e especializado, nas estações verão e primavera (Figura 1). Porém, nota-se que as combinações dessas estações com os níveis de menor especialização migraram para o grupo II. Essa migração pode ser explicada pelas diferenças no manejo nutricional entre os diferentes extratos produtivos. Os sistemas mais especializados necessitaram desocupar áreas antes destinadas ao pastejo, para destiná-las ao plantio do milho, entre a primavera e o verão, o que resultou em diminuição do fornecimento de forrageiras frescas, em razão do aumento da oferta de silagem de milho e concentrado. Isso manteve esses sistemas de produção no grupo III (Figura 1), principalmente em razão dos maiores valores de $\Sigma \mathrm{n} 6: \mathrm{n} 3$ (variação explicada

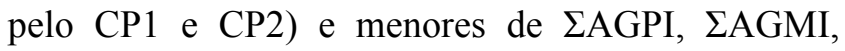
ácido rumênico e ácido t10,c12-octadecadienoico, em comparação ao grupo II (variação explicada principalmente pelo $\mathrm{CP} 1$ ).

Esse manejo nutricional, entretanto, não ocorreu em propriedades dos extratos produtivos menos especializados, que apresentaram menor ou nenhum fornecimento de silagem de milho na dieta (Tabela 1).
O extrato semiespecializado, que também utiliza silagem de milho e concentrado, mas em menores proporções, apesar de situar-se no grupo II, deslocouse em direção ao grupo III (Figura 1), o que corrobora a explicação anterior.

No grupo II, além das combinações dos sistemas semiespecializados e não especializados com as estações primavera e verão, ocorreram todas as combinações dos extratos produtivos com a estação inverno, exceto para a combinação inverno-não especializado, que foi o único representante do grupo I, caracterizado pelo leite de maior potencial nutracêutico. Essa variação foi explicada principalmente pelo CP1, já que esses grupos diferiram minimamente quanto ao CP2.

\section{Conclusões}

1. Os sistemas de produção e as estações do ano interferem conjuntamente no perfil de ácidos graxos do leite bovino, mas isoladamente em sua qualidade físico-química e microbiológica.

2. As maiores contagens de células somáticas e os menores valores de proteína são obtidos no verão e, com a diminuição do grau de especialização das unidades produtoras, a contagem bacteriana total aumenta.

3. Os leites bovinos de maior potencial nutracêutico são obtidos no inverno, nos sistemas não especializados de produção, que apresentam os maiores teores de ácidos graxos poli-insaturados, ácido rumênico e ácido t10,c12-octadecadienoico.

4. O sistema de produção não especializado, no inverno, apresenta os melhores índices de aterogenicidade, trombogenicidade, razão de ácidos graxos hipocolesterolêmicos e hipercolesterolêmicos e, em especial, o melhor índice nutracêutico.

5. Em razão de sua alta capacidade em diferenciar alterações no manejo nutricional dos animais, o índice nutracêutico deve ser preferido para a avaliação da qualidade da fração lipídica do leite bovino.

\section{Agradecimentos}

À Fundação de Amparo à Pesquisa do Estado do Rio Grande do Sul (Fapergs), à Coordenação de Aperfeiçoamento de Pessoal de Nível Superior (Capes) e ao Conselho Nacional de Desenvolvimento Científico e Tecnológico (CNPq), pelo apoio e auxílio financeiro prestados. 


\section{Referências}

BLIGH, E.G.; DYER, W.J. A rapid method of total lipid extraction and purification. Canadian Journal of Biochemistry and Physiology, v.37, p.911-917, 1959. DOI: 10.1139/o59-099.

BODENMÜLLER FILHO, A.; DAMASCENO, J.C.; PREVIDELLI, I.T.S.; SANTANA, R.G.; RAMOS, C.E.C. de O.; SANTOS, G.T. dos. Tipologia de sistemas de produção baseada nas características do leite. Revista Brasileira de Zootecnia, v.39, p.1832-1839, 2010. DOI: 10.1590/S1516-35982010000800028.

CHILLIARD, Y.; GLASSER, F.; FERLAY, A.; BERNARD, L.; ROUEL, J.; DOREAU, M. Diet, rumen biohydrogenation and nutritional quality of cow and goat milk fat. European Journal of Lipid Science and Technology, v.109, p.828-855, 2007. DOI: 10.1002/ejlt.200700080.

CHRISTIE, W.W. A simple procedure for rapid transmethylation of glycerolipids and cholesteryl esters. Journal of Lipid Research, v.23, p.1072-1077, 1982.

COSTA, R.G.; MESQUITA, Í.V.U.; QUEIROGA, R. de C.R. do E.; MEDEIROS, A.N. de; CARVALHO, F.F.R. de; BELTRÃO FILHO, E. Características químicas e sensoriais do leite de cabras Moxotó alimentadas com silagem de maniçoba. Revista Brasileira de Zootecnia, v.37, p.694-702, 2008. DOI: 10.1590/ S1516-35982008000400016.

DEWHURST, R.J.; SHINGFIELD, K.J.; LEE, M.R.F.; SCOLLAN, N.D. Increasing the concentrations of beneficial polyunsaturated fatty acids in milk produced by dairy cows in high-forage systems. Animal Feed Science and Technology, v.131, p.168-206, 2006. DOI: 10.1016/j.anifeedsci.2006.04.016.

FANTI, M.G.N.; ALMEIDA, K.E. de; RODRIGUES, A.M.; SILVA, R.C. da; FLORENCE, A.C.R.; GIOIELLI, L.A.; OLIVEIRA, M.N. de. Contribuição ao estudo das características físico-químicas e da fração lipídica do leite orgânico. Ciência e Tecnologia de Alimentos, v.28, p.259-265, 2008. DOI: 10.1590/ S0101-20612008000500039.

GABBI, A.M.; MCMANUS, C.M.; SILVA, A.V.; MARQUES, L.T.; ZANELA, M.B.; STUMPF, M.P.; FISCHER, V. Typology and physical-chemical characterization of bovine milk produced with different productions strategies. Agricultural Systems, v.121, p.130-134, 2013. DOI: 10.1016/j.agsy.2013.07.004.

HAUG, A.; HØSTMARK, A.T.; HARSTAD, O.M. Bovine milk in human nutrition - a review. Lipids in Health and Disease, v.25, p.1-16, 2007. DOI: 10.1186/1476-511x-6-25.

KRATZ, M.; BAARS, T.; GUYENET, S. The relationship between high-fat dairy consumption and obesity, cardiovascular, and metabolic disease. European Journal of Nutrition, v.52, p.1-24, 2013. DOI: 10.1007/s00394-012-0418-1.

LAHLOU, M.N.; KANNEGANTI, R.; MASSINGILL, L.J.; BRODERICK, G.A.; PARK, Y.; PARIZA, M.W.; FERGUSON, J.D.; WU, Z. Grazing increases the concentration of CLA in dairy cow milk. Animal, v.8, p.1191-1200, 2014. DOI: 10.1017/ S1751731114000998.

ROY, A.; FERLAY, A.; SHINGFIELD, K.J.; CHILLIARD, Y. Examination of the persistency of milk fatty acid composition responses to plant oils in cows given different basal diets, with particular emphasis on trans-C18:1 fatty acids and isomers of conjugated linoleic acid. Animal Science, v.82, p.479-492, 2006. DOI: $10.1079 / \operatorname{asc} 200658$.

SANTOS-SILVA, J.; BESSA, R.J.B.; SANTOS-SILVA, F. Effect of genotype, feeding system and slaughter weight on the quality of light lambs: II. Fatty acid composition of meat. Livestock Production Science, v.77, p.187-194, 2002. DOI: 10.1016/ S0301-6226(02)00059-3.

SHOOK, G.E. Genetic improvement of mastitis through selection on somatic cell count. Veterinary Clinics of North America: Food Animal Practice, v.9, p.563-581, 1993.

SIMIONATO, J.I.; GARCIA, J.C.; SANTOS, G.T. dos; OLIVEIRA, C.C.; VISENTAINER, J.V.; SOUZA, N.E. de. Validation of the determination of fatty acids in milk by gas chromatography. Journal of the Brazilian Chemical Society, v.21, p.520-524, 2010. DOI: 10.1590/S0103-50532010000300018.

SIMOPOULOS, A.P. Evolutionary aspects of diet, the omega-6/ omega-3 ratio and genetic variation: nutritional implications for chronic diseases. Biomedicine and Pharmacotherapy, v.60, p.502-507, 2006. DOI: 10.1016/j.biopha.2006.07.080.

TRIPATHI, M.K. Effect of nutrition on production, composition, fatty acids and nutraceutical properties of milk. Advances in Dairy Research, v.2, p.1-11, 2014. DOI: 10.4172/2329-888X.1000115.

ULBRICHT, T.L.V; SOUTHGATE, D.A.T. Coronary heart disease: seven dietary factors. Lancet, v.338, p.985-992, 1991. DOI: 10.1016/0140-6736(91)91846-M.

VARGAS, D.P. de; NÖRNBERG, J.L.; MELLO, R. de O.; SHEIBLER, R.B.; MILANI, M.P.; MELLO, F.C.B. Correlações entre contagem bacteriana total e parâmetros de qualidade do leite. Revista Brasileira de Ciência Veterinária, v.20, p.241-247, 2013.

VARGAS, D.P. de; NÖRNBERG, J.L.; MELLO, R. de O.; SHEIBLER, R.B.; BREDA, F.C.; MILANI, M.P. Correlações entre contagem de células somáticas e parâmetros físico-químicos e microbiológicos de qualidade do leite. Ciência Animal Brasileira, v.15, p.473-483, 2014. DOI: 10.4322/rbcv.2014.009.

Recebido em 13 de janeiro de 2015 e aprovado em 6 de outubro de 2015

Pesq. agropec. bras., Brasília, v.50, n.12, p.1208-1219, dez. 2015 DOI: $10.1590 / \mathrm{S} 0100-204 X 2015001200011$ 